\title{
Minireview
}

\section{Intensity-modulated radiation therapy: emerging cancer treatment technology}

\author{
TS Hong', MA Ritter', WA Tomé ${ }^{1,2}$ and PM Harari*,1 \\ 'Department of Human Oncology, University of Wisconsin Medical School, Madison, WI, USA; ${ }^{2}$ Department of Medical Physics, University of Wisconsin \\ Medical School, Madison, WI, USA
}

\begin{abstract}
The use of intensity-modulated radiation therapy (IMRT) is rapidly advancing in the field of radiation oncology. Intensity-modulated radiation therapy allows for improved dose conformality, thereby affording the potential to decrease the spectrum of normal tissue toxicities associated with IMRT. Preliminary results with IMRT are quite promising; however, the clinical data is relatively immature and overall patient numbers remain small. High-quality IMRT requires intensive physics support and detailed knowledge of threedimensional anatomy and patterns of tumour spread. This review focuses on basic principles, and highlights the clinical implementation of IMRT in head and neck and prostate cancer.

British Journal of Cancer (2005) 92, I819- 1824. doi: I0.1038/sj.bjc.6602577 www.bjcancer.com
\end{abstract}

Published online 26 April 2005

(C) 2005 Cancer Research UK

Keywords: intensity-modulated radiation therapy; head and neck cancer; prostate cancer

Intensity-modulated radiation therapy (IMRT) represents a promising new advance in the field of radiation oncology. Intensity-modulated radiation therapy allows for improved 'shaping' of radiation dose profiles around tumour and at-risk nodal structures while sparing adjacent normal tissue structures. This capacity for improved dose distribution affords considerable opportunity to reduce the overall toxicity profile associated with radiation therapy. The use of IMRT is advancing rapidly worldwide as this technology has become commercially available. Despite considerable promise, IMRT use remains in relatively early stages, and must be delivered with strict attention to quality assurance as the clinical data and patient follow-up mature. Furthermore, IMRT is quite labour-intensive, with strong dependence on physics and quality assurance support, thus leaving open the possibility for significant heterogeneity in the precision of IMRT practice.

\section{What is IMRT?}

Intensity-modulated radiation therapy refers to a specific technique of linear accelerator-based radiation therapy whereby beams are modulated in such a manner to produce highly conformal dose distributions. A primary objective of IMRT is to reduce dose to selected normal tissue structures in an effort to preserve function, while maintaining full dose delivery to tumour targets. For

\footnotetext{
*Correspondence: Dr PM Harari, Department of Human Oncology, University of Wisconsin Hospital and Clinics, 600 Highland Avenue K4/ 332, Madison, WI 53792, USA; E-mail: harari@humonc.wisc.edu

Received I January 2005; revised 15 March 2005; accepted 16 March 2005; published online 26 April 2005
}

example, in conventional head and neck $(\mathrm{H} \& \mathrm{~N})$ radiotherapy, static fields are shaped by blocks and modulated by simple beam wedges or tissue compensators (Harari et al, 1998). In contrast, IMRT is delivered by individually modulated fields (step and shoot or sliding window technique) or by a rotating linear accelerator gantry (serial or helical tomotherapy). Variable dose intensities can be delivered through the segments of each treatment field, thereby maximizing conformality of the ultimate dose distribution.

Intensity-modulated radiation therapy planning is conceptually distinct from conventional radiotherapy planning. For both conventional (3D conformal radiation therapy, 3D-CRT) and IMRT planning, the radiation oncologist designates specific targets (gross tumour, elective nodal regions) and avoidance structures (rectal wall, bladder, spinal cord, salivary glands, optic apparatus, etc.). In 3D-CRT, simple beam arrangements are used with generous field margins to account for daily set-up variation and physical characteristics of the beam itself. The radiation dose and profile is then calculated in a process known as forward planning. In contrast, IMRT planning requires that the physician define dose specifications for both the target and avoidance structures. The computer planning software then creates a series of modulation patterns at each beam angle that strive to achieve the physician's dose prescription goals. This process is known as inverse planning.

\section{Brief history of IMRT}

Intensity-modulated radiation therapy was first conceptualised in the 1960s. However, it was not until the 1980s-1990s that the computing capability required for complex inverse planning algorithms became commercially available (Intensity Modulated Radiation Therapy Collaborative Working Group, 2001). In 1994, the NOMOS Peacock system was introduced as the first commercial IMRT delivery unit. The Peacock system required the use of a beam modulation device known as a dynamic 
multivane intensity-modulating collimator (MIMiC). This particular form of IMRT is called serial tomotherapy, as 'slices' could be treated by a continually rotating gantry (Intensity Modulated Radiation Therapy Collaborative Working Group, 2001). Step and shoot IMRT represents another commonly used technique whereby multiple static beams are subdivided into 'segments'. In the sliding window technique, a window defined by the MLC leaves sweeps across the treatment field at variable speed, while the monitor units are delivered continuously (Ling et al, 1996). With serial and helical tomotherapy, the intensity modulation is achieved through the use of a binary MLC (radiation is either delivered or not). In contrast to serial tomotherapy, helical tomotherapy is characterised by translation of the treatment couch during treatment delivery, allowing large field lengths to be treated in a single spiral (Mackie et al, 1999). Moreover, a CT detector array diametrically opposed to the energy source allows for image and dose reconstruction capabilities during treatment. Each of these systems shares commonality of need for intensive physics support, precise anatomical target definition, and rigorous quality assurance (Richardson et al, 2003; Fenwick et al, 2004).

\section{CLINICAL IMPLICATIONS}

Clinical research efforts in IMRT have generally considered two basic paradigms. The first research strategy seeks to maintain current tumour control rates while decreasing toxicity profiles. For example, IMRT studies in $\mathrm{H} \& \mathrm{~N}$ cancer commonly strive to maintain conventional dose to primary tumour and at-risk nodal regions, while diminishing dose to adjacent normal tissue structures such as salivary glands and spinal cord. The second strategy attempts to escalate tumour target dose while maintaining acceptable levels of toxicity. This approach has been taken in doseescalation and hypofractionation trials for prostate cancer and more recently in lung cancer. Regardless of the primary objective, precise, reproducible accurate patient/target set-up and rigorous physics quality assurance are critical to successful IMRT delivery. In this review, we highlight the role of IMRT in two of the most common anatomic sites of current use; $\mathrm{H} \& \mathrm{~N}$ and prostate cancer.

\section{Clinical applications in $\mathrm{H} \& \mathrm{~N}$ cancer}

Radiation plays a central role in the treatment of $\mathrm{H} \& \mathrm{~N}$ cancer. New radiation delivery techniques offer powerful potential to diminish the spectrum and severity of radiation toxicities for $\mathrm{H} \& \mathrm{~N}$ cancer patients. For many decades, conventional H\&N radiation techniques have involved treatment with generous opposed lateral beams to encompass the known primary tumour and upper cervical lymphatics. This classical technique produces a relatively homogeneous dose distribution that allows excellent target dosing while minimizing hot and cold spots. However, due to the tight proximity of tumour targets and normal tissue in the $\mathrm{H} \& \mathrm{~N}$ region, many uninvolved structures including salivary glands, spinal cord, auditory apparatus, optic apparatus, mandible, and vocal cords can unnecessarily receive high doses of radiation.

In H\&N cancer, one of the most common rationales for IMRT is to preserve salivary gland function and thereby diminish the severity of chronic xerostomia with associated adverse impact on taste, swallowing, dentition, speech, and overall quality of life. In addition, the capacity of IMRT to limit dose to normal tissue structures may also allow dose escalation and differential dose painting, thereby accomplishing 'in-field tumour boosting' (Butler et al, 1999).

Early reports have described clinical promise with H\&N IMRT, both for tumour control and reduction of xerostomia. However, these data generally represent limited single-institution experience, often with heterogeneous cohorts of patients (postoperative vs definitive, chemotherapy $v s$ no chemotherapy, varying dose/ fractionation schemes). Prospective, multiinstitutional protocols that incorporate IMRT for $\mathrm{H} \& \mathrm{~N}$ cancer patients remain in very early stages.

More mature clinical data regarding the efficacy of IMRT in the management of H\&N cancer is now emerging. Preliminary singleinstitution experience with IMRT suggests favourable outcome. While these results can be interpreted with caution, given the small overall numbers and careful patient selection, they suggest that H\&N IMRT appears to be safe and effective in appropriately selected patients.

The Washington University experience with H\&N IMRT included 126 patients (Chao et al, 2003). In total, $41 \%$ of patients were treated definitively and the remainder postoperatively. The 2year actuarial locoregional control rate was $85 \%$. Patterns of recurrence from patients treated at the University of Michigan with parotid sparing H\&N IMRT techniques were recently reported (Dawson et al, 2000). A total of 58 patients with primary $\mathrm{H} \& \mathrm{~N}$ cancer were treated definitively or postoperatively and followed for a median of 27 months. A $79 \%$ local rate of control was achieved with 12 patients developing recurrence by 2 years. Investigators at Baylor reported on 20 patients with primary $\mathrm{H} \& \mathrm{~N}$ tumours showing 19 patients with a complete response to therapy and a significant reduction of dose to parotid glands (Butler et al, 1999). With a median follow-up of 13.5 months, two patients who achieved complete response developed local recurrence at 10 and 15 months. Treatments were generally well tolerated. Lee et al (2002) reported on 67 patients with nasopharyngeal carcinoma who were treated with IMRT. Of 58 patients, 50 were treated with concomitant and adjuvant chemotherapy. With a median followup of 31 months, a local regional progression-free rate of $98 \%$ was observed. A recent update with 118 patients continues to demonstrate excellent locoregional control rates (Bucci et al, 2004). These results have stimulated further evaluation of $\mathrm{H} \& \mathrm{~N}$ IMRT in an ongoing cooperative group trial for nasopharynx cancer patients through the Radiation Therapy Oncology Group.

Xerostomia brings significant long-term consequences for the $\mathrm{H} \& \mathrm{~N}$ cancer patient. Lack of salivary production can lead to sore throat, decreased taste, dental decay, mandibular osteoradionecrosis, and impaired voice and swallowing functioning. Intensitymodulated radiation therapy techniques afford distinct opportunities for salivary gland sparing (Figure 1). Investigators at the University of Michigan suggest that mean doses of $\leqslant 26$ Gy to the parotid gland may afford substantial sparing of long-term parotid gland function. At $\leqslant 26 \mathrm{~Gy}$, excellent preservation of salivary function (unstimulated and stimulated, respectively) was observed (Eisbruch et al, 1999). This group has also demonstrated that salivary flow correlates with improved quality of life, suggesting that parotid sparing may be associated with improved overall clinical outcome (Eisbruch et al, 2001). Chao et al (2001) have reported on results of a trial examining the functional outcome of salivary glands at 6 months following radiation. Mean dose to the parotid gland was shown to correlate with ultimate salivary flow in 41 patients analysed. More recent studies continue to suggest that salivary sparing is possible with IMRT using proper technique (Astreinidou et al, 2004) and may favourably impact overall quality of life (Reddy et al, 2001; Parliament et al, 2004).

While these studies suggest that IMRT represents a promising new therapy in H\&N cancer, early results must be viewed with some caution. Aside from the nasopharynx data, these series include a heterogeneous group of $\mathrm{H} \& \mathrm{~N}$ patients, some treated definitively and some postoperatively. Chemotherapy regimens and fractionation regimens vary within and across the published series. Overall follow-up for the patients remains relatively short. The specific techniques of IMRT treatment show evolution within each of these updated series. These factors suggest that ongoing careful and systematic evaluation regarding acute and long-term outcomes with H\&N IMRT should be pursued. Data are emerging regarding key contributing factors for disease control and 

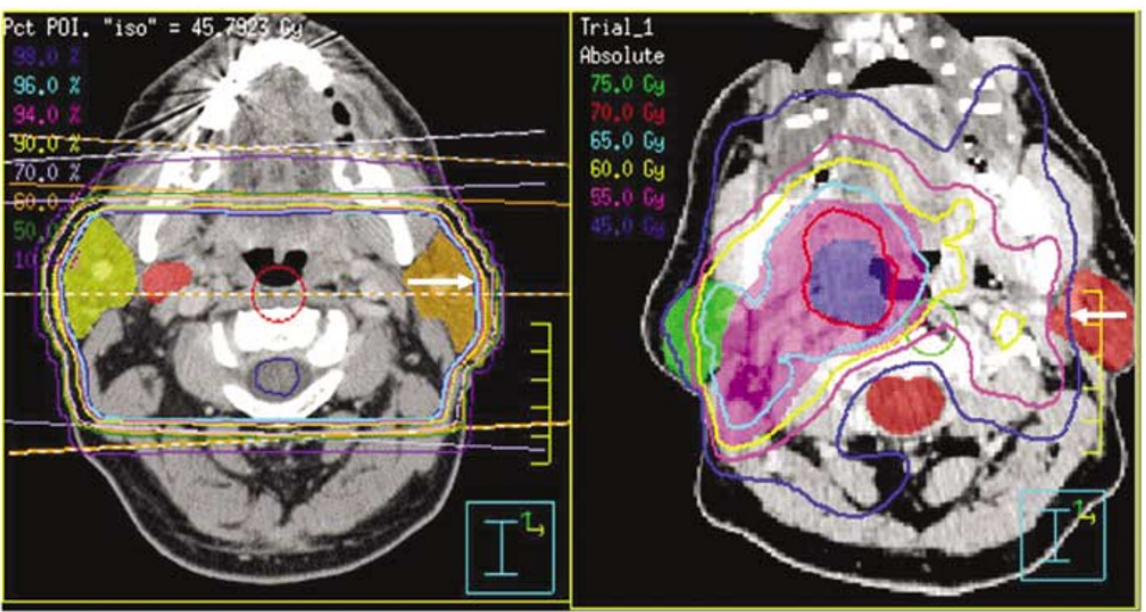

Figure I Isodose distributions contrasting conventional (left) and IMRT (right) H\&N treatment plans. Significant reduction of dose to the left parotid gland is achieved with the IMRT plan.

treatment failure for H\&N IMRT, including tumour characteristics and treatment technique. Chao et al (2004) identified that primary tumour GTV and nodal GTV size independently predicted for therapeutic outcome. Patterns of failure analysis in patients treated with IMRT led Eisbruch et al (2004) to recommend careful attention to retropharyngeal nodes in patients with oropharyngeal primaries. Further reports based on clinical outcome will continue to shape the practice of H\&N IMRT.

\section{Clinical applications in prostate cancer}

The past decade has provided new data regarding of the importance of dose escalation in the treatment of localised prostate cancer. Pollack et al (2002) reported results of a seminal phase III study of dose escalation at the MD Anderson Cancer Center. Patients with low- or intermediate risk localised prostate cancer were randomised to 70 vs $78 \mathrm{~Gy}$. The high dose arm showed a statistically significant improvement in freedom-from-failure. These results are further supported by several single-institution series (Zelefsky et al, 1998a, b; Pollack et al, 2004).

Escalation of radiation dose to the prostate brings increased toxicity risks, particularly rectal complications. When delivered with conventionally planned techniques, doses higher than $70 \mathrm{~Gy}$ are associated with higher complication rates (Pollack et al, 2002; Tucker et al, 2004). It has now become clear that 3D conformal radiotherapy techniques allow improved overall treatment tolerance of higher doses (Nguyen et al, 1998; Zelefsky et al, 1998a, b; Michalski et al, 2000) but complication rates, particularly rectal bleeding, can remain substantial. Several analyses suggest that the total volume of rectal wall exposed to greater than $60-70 \mathrm{~Gy}$ predicts the rate of grade 2 (rectal bleeding) or more severe complications. Therefore, the implementation of IMRT, with the ability to further reduce rectal dose (Figure 2), should further reduce toxicities, as has recently been reported (Zelefsky et al, 2002).

Increasing the conformality of radiation dose requires increased set-up precision. In recent years, transabdominal ultrasound systems have been employed to more accurately target the prostate on a daily basis (Lattanzi et al, 1999; Lattanzi et al, 2000; D'Amico et al, 2001). As an alternative, the implantation of small metal seeds into the prostate to serve as fiduciaries during daily portal imaging has also proven reliable as a means of reproducibly localising the prostate (Nederveen et al, 2003). In addition, it has been demonstrated that the use of a rectal balloon catheter can immobilise the prostate and facilitate localisation on port films potentially allowing tighter margins for the treatment volume (Wachter et al, 2002). Further, the lateral and posterior aspects of the rectal wall are partially displaced out of the high dose region by the rectal balloon, which offers the potential for significant rectal dose sparing (Patel et al, 2003).

A number of centres have sought to reduce the number of fractions required for prostate cancer treatment by increasing fraction size. While the rationale has been primarily for logistical and resource utilisation purposes in the past, it has recently become better appreciated that prostate cancer may have unique radiobiological properties (increased ability to repair damage). It may, therefore, prove advantageous to use larger daily fractions of $>2.0 \mathrm{~Gy}$ (hypofractionation), rather than conventional $1.8-2.0 \mathrm{~Gy}$ fractions commonly employed, when treating most other tumour types. Using linear quadratic formulation, one can predict an improved ratio of tumour control to normal tissue toxicity (the therapeutic ratio) for prostate cancer by using hypofractionation (Fowler et al, 2001). Cleveland Clinic investigators have carried out a trial of hypofractionation consisting of 28 fractions of $2.5 \mathrm{~Gy}$ for a total dose of $70 \mathrm{~Gy}$ (Kupelian et al, 2002). Intensity modulated radiotherapy and daily pretreatment ultrasound-based prostate localisation were employed to improve treatment precision and reduce radiation dose to the rectum. These early results appear to indicate disease control (PSA recurrence-free survival) at least equivalent to that seen with standard fractionation, although follow-up remains short. Given the smaller number of larger radiation doses delivered, highly conformal and accurate radiation techniques like image-guided IMRT afford the opportunity for the exploration of novel fractionation regimens, which ultimately may improve local control and cost-effectiveness. However, with the delivery of fewer treatment fractions, errors incurred through daily set-up variations or internal organ motion with each fraction will have a larger impact on overall treatment, and therefore there is clear need for high precision patient localisation techniques with such treatment strategies (Keller et al, 2004; Orton and Tome, 2004).

\section{IMRT precautions}

As with any new technology, there is enthusiasm mixed with caution regarding the use of IMRT. Some have voiced concern regarding the embracement of IMRT as a standard approach until the completion and comparative evaluation of systematic clinical trials (Halperin, 2000; Glatstein, 2003). Nevertheless, the global use of IMRT has increased dramatically over the last several 


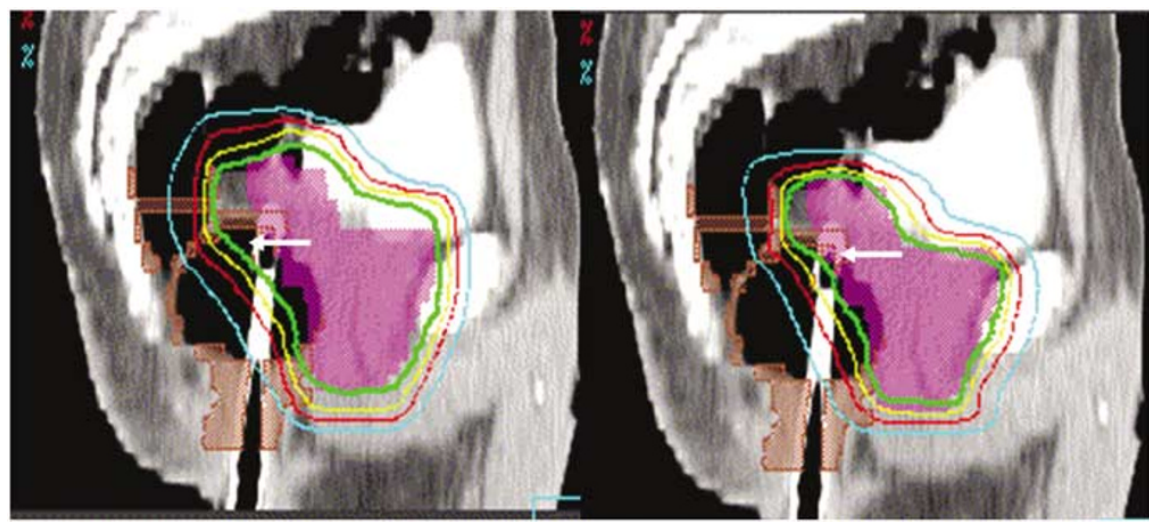

Figure 2 Isodose distributions contrasting conventional 3D conformal (left) and IMRT (right) prostate treatment plans. The arrows highlight improved conformality to the prostate and seminal vesicles and decreased rectal volume receiving high dose with the IMRT plan.

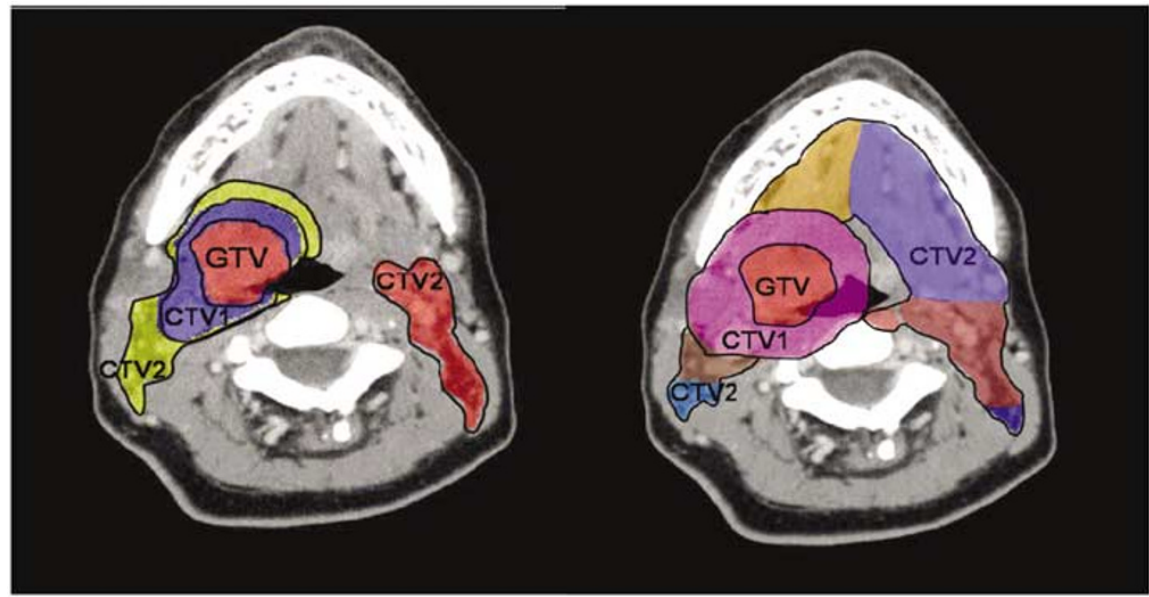

Figure 3 Variations in H\&N target delineation. Highly distinct CTV designs from two H\&N experts which illustrate broad variation in target delineation strategies for the identical tonsil case.

years. In a recent survey of US radiation oncologists published by Mell et al (2003), one-third of respondents reported that they were currently using IMRT. In addition, over $90 \%$ of respondents who were not currently using IMRT stated that they planned to do so in the near future. Despite increased utilisation, several notes of caution regarding the use of IMRT are worthy of mention.

IMRT standardisation There exists a lack of global standardisation in IMRT planning and delivery. The literature describes several distinct IMRT techniques, and several aspects of the IMRT planning processes remain highly practitioner dependent. A variety of fractionation regimens and target delineation techniques are in common use. In a recent study, substantial variation in both target delineation and fractionation recommendations were observed among worldwide $\mathrm{H} \& \mathrm{~N}$ experts when provided the identical tonsil cancer case (Figure 3) (Hong et al, 2004). Subtle technique distinctions can pose considerable challenge to new institutions that wish to commence use of IMRT. For these reasons, it is increasingly important to provide standardised recommendations and guidelines for IMRT planning. Indeed, guidelines are beginning to emerge with specific recommendations for nodal coverage targets based on tumour location and stage (Eisbruch et al, 2002; Gregoire et al, 2003; Levendag et al, 2004).
IMRT set-up precision Radiation oncologists have been traditionally trained to use large field margins to cover unsuspected tumour infiltration and to avoid geographical miss. Since a major goal of IMRT is to limit dose to normal tissue structures that often reside very close to tumour targets, daily set-up precision takes on much greater significance. A recent study suggests that the daily set-up variations with conventional $\mathrm{H} \& \mathrm{~N}$ masking and immobilisation techniques may be insufficient to ensure high-quality IMRT delivery over a 6-7 week course of treatment (Hong et al, 2005). Indeed, daily set-up errors of several $\mathrm{mm}$ can result in underdosing of tumour or overdosing of normal tissues such as the 'spared' parotid gland, underscoring the importance of rigorous quality assurance processes for IMRT.

Radiation exposure Another theoretical concern with IMRT involves the increased machine output (monitor units) required for IMRT delivery and the potential for increased radiation exposure. With increased modulation of the radiation beam, more monitor units are generated to deliver the prescribed dose. Consequently, there can be increased leakage from the linear accelerator, increasing the total body exposure by $2-3$ fold (Hall and Wuu, 2003). In a recent publication, Hall et al suggest that this increase in total body dose could potentially increase the rate of second malignancy from $1 \%$ per 10 years to $1.75 \%$ per 10 years, an 
almost doubling of the second malignancy rate. Careful follow-up will be required to determine if IMRT does in fact enhance this risk.

Future IMRT trials As H\&N IMRT steadily advances into more common use, the design of clinical trials that explore the use of chemoradiation, altered fractionation, and molecular targeted therapy becomes more complex. Indeed, the cooperative oncology groups are struggling currently with systematic methodology to credential and quality-assure the process of H\&N IMRT for participating institutions. The successful accomplishment of future $\mathrm{H} \& \mathrm{~N}$ cancer treatment trials will need to acknowledge the increasing use of IMRT despite inherent difficulties in trial design and quality assurance. This represents a significant challenge in that a broad series of promising molecular agents, that may enhance radiation response are becoming available. However, the profound variation in IMRT expertise and delivery technique across institutions currently renders this an added variable that serves to complicate the evaluation of new molecular agents with radiation.

In prostate cancer, novel hypofractionated regimens have been proposed to exploit radiobiological properties with significant shortening of treatment time without loss of efficacy or increase in toxicity (Fowler et al, 2003). Indeed, investigators are exploring the utility of IMRT in a number of other clinical scenarios, including brain tumours, lung cancer, upper GI malignancies, breast cancer, gynaecologic malignancies, and many other sites. The primary objectives focus on reduction of toxicity and/or increased dose to the tumour target.

\section{REFERENCES}

Astreinidou E, Dehnad H, Terhaard CH, Raaijmakers CP (2004) Level II lymph nodes and radiation-induced xerostomia. Int J Radiat Oncol Biol Phys 58: $124-131$

Bucci M, Xia P, Lee N, Fischbein N, Kramer A, Weinberg V, Akazawa C, Cabrera A, Fu KK, Quivey JM (2004) Intensity modulated radiation therapy for carcinoma of the nasopharynx: an update of the UCSF experience. Int J Radiat Oncol Biol Phys 60: S317-S318

Butler EB, Teh BS, Grant III WH, Uhl BM, Kuppersmith RB, Chiu JK, Donovan DT, Woo SY (1999) Smart (simultaneous modulated accelerated radiation therapy) boost: a new accelerated fractionation schedule for the treatment of head and neck cancer with intensity modulated radiotherapy. Int J Radiat Oncol Biol Phys 45: 21 - 32

Chao KS, Deasy JO, Markman J, Haynie J, Perez CA, Purdy JA, Low DA (2001) A prospective study of salivary function sparing in patients with head-and-neck cancers receiving intensity-modulated or three-dimensional radiation therapy: initial results. Int J Radiat Oncol Biol Phys 49: 907-916

Chao KS, Ozyigit G, Blanco AI, Thorstad WL, Deasy JO, Haughey BH, Spector GJ, Sessions DG (2004) Intensity-modulated radiation therapy for oropharyngeal carcinoma: impact of tumor volume. Int J Radiat Oncol Biol Phys 59: $43-50$

Chao KS, Ozyigit G, Tran BN, Cengiz M, Dempsey JF, Low DA (2003) Patterns of failure in patients receiving definitive and postoperative IMRT for head-and-neck cancer (see comment). Int J Radiat Oncol Biol Phys 55: 312-321

D'Amico AV, Manola J, Loffredo M, Lopes L, Nissen K, O'Farrell DA, Gordon L, Tempany CM, Cormack RA (2001) A practical method to achieve prostate gland immobilization and target verification for daily treatment. Int J Radiat Oncol Biol Phys 51: 1431-1436

Dawson LA, Anzai Y, Marsh L, Martel MK, Paulino A, Ship JA, Eisbruch A (2000) Patterns of local-regional recurrence following parotid-sparing conformal and segmental intensity-modulated radiotherapy for head and neck cancer. Int J Radiat Oncol Biol Phys 46: 1117-1126

Eisbruch A, Foote RL, O'Sullivan B, Beitler JJ, Vikram B (2002) Intensitymodulated radiation therapy for head and neck cancer: emphasis on the selection and delineation of the targets. Seminars in Radiation Oncology 12: $238-249$
Other new aspects of IMRT research include the integration of sophisticated image-guidance. As discussed previously, the steep dose gradients created by IMRT plans can increase the risk of geographical target miss or unintentional overdosing of spared structures. Recent technologies such as ultrasound position verification, cone beam CT, and MVCT with helical tomotherapy offer methods to 'visualise' daily treatment set-up and reduce setup variability and resultant dosimetric uncertainty (Mackie et al, 2003). Indeed, high-quality IMRT is highly dependent on accurate and reproducible patient set-up.

\section{Future directions and conclusions}

There is no question that the use of IMRT in modern cancer therapy is expanding worldwide. This promising technology advancement brings clear opportunity to improve the therapeutic ratio for cancer patient outcome. The early clinical reports to date are quite promising for several distinct tumour types. However, improved definition of those specific parameters (tumour and normal tissue) that render patients most likely to truly benefit from IMRT will be valuable. The time, expense, and expertise required to realise optimised and reproducible IMRT delivery across institutions warrants acknowledgement regarding the most appropriate usage and necessary quality assurance processes to ensure patient benefit and safety. The systematic accumulation of clinical data is of great importance for advancement in this field. Ideally, this data will come in the form of controlled clinical trials that rigorously examine not just radiation physics and dosimetry, but acute and late normal tissue effects with long term clinical follow up.

Eisbruch A, Kim HM, Terrell JE, Marsh LH, Dawson LA, Ship JA (2001) Xerostomia and its predictors following parotid-sparing irradiation of head-and-neck cancer. Int J Radiat Oncol Biol Phys 50: $695-704$

Eisbruch A, Marsh LH, Dawson LA, Bradford CR, Teknos TN, Chepeha DB, Worden FP, Urba S, Lin A, Schipper MJ, Wolf GT (2004) Recurrences near base of skull after IMRT for head-and-neck cancer: implications for target delineation in high neck and for parotid gland sparing. Int J Radiat Oncol Biol Phys 59: 28-42

Eisbruch A, Ten Haken RK, Kim HM, Marsh LH, Ship JA (1999) Dose, volume, and function relationships in parotid salivary glands following conformal and intensity-modulated irradiation of head and neck cancer (see comment). Int J Radiat Oncol Biol Phys 45: 577-587

Fenwick JD, Tome WA, Jaradat HA, Sui SK, James JA, Balog JP, DeSouza CN, Lucas DB, Olivera GA, Mackie TR, Paliwal BR (2004) Quality assurance of a helical tomotherapy machine. Phys Med Biol 49: $2933-2953$

Fowler J, Chappell R, Ritter M (2001) Is alpha/beta for prostate tumors really low? Int J Radiat Oncol Biol Phys 50: 1021 - 1031

Fowler JF, Ritter MA, Chappell RJ, Brenner DJ (2003) What hypofractionated protocols should be tested for prostate cancer? Int J Radiat Oncol Biol Phys 56: $1093-1104$

Glatstein E (2003) The return of the snake oil salesmen (see comment). Int J Radiat Oncol Biol Phys 55: $561-562$

Gregoire V, Levendag P, Ang KK, Bernier J, Braaksma M, Budach V, Chao C, Coche E, Cooper JS, Cosnard G, Eisbruch A, El-Sayed S, Emami B, Grau C, Hamoir M, Lee N, Maingon P, Muller K, Reychler H (2003) CTbased delineation of lymph node levels and related CTVs in the nodenegative neck: DAHANCA, EORTC, GORTEC, NCIC,RTOG consensus guidelines. Radiother Oncol 69: 227-236

Hall EJ, Wuu CSIHEJ (2003) Radiation-induced second cancers: the impact of 3D-CRT and IMRT. Int J Radiat Oncol Biol Phys 56: 83-88

Halperin EC (2000) Overpriced technology in radiation oncology. Int $J$ Radiat Oncol Biol Phys 48: $917-918$

Harari PM, Sharda NN, Brock LK, Paliwal BR (1998) Improving dose homogeneity in routine head and neck radiotherapy with custom 3-D compensation. Radiother Oncol 49: 67-71 
Hong TS, Tome WA, Chappell R, Harari PM (2005) The impact of daily setup variations on head and neck IMRT. Int J Radiat Oncol Biol Phys 69: $779-788$

Hong TS, Tome WA, Chappell RJ, Harari PM (2004) Variation in target delineation for head and neck IMRT: An international multi-institutional study. Int J Radiat Oncol Biol Phys 60: S157-S158

Intensity Modulated Radiation Therapy Collaborative Working Group (2001) Intensity-modulated radiotherapy: current status and issues of interest (see comment). Int J Radiat Oncol Biol Phys 51: 880-914

Keller H, Tome W, Ritter MA, Mackie TR (2004) Design of adaptive treatment margins for non-negligible measurement uncertainty: application to ultrasound-guided prostate radiation therapy. Phys Med Biol 49: 69-86

Kupelian PA, Reddy CA, Carlson TP, Altsman KA, Willoughby TR (2002) Preliminary observations on biochemical relapse-free survival rates after short-course intensity-modulated radiotherapy (70 Gy at $2.5 \mathrm{~Gy} /$ fraction) for localized prostate cancer. Int J Radiat Oncol Biol Phys 53: 904-912

Lattanzi J, McNeeley S, Donnelly S, Palacio E, Hanlon A, Schultheiss TE, Hanks GE (2000) Ultrasound-based stereotactic guidance in prostate cancer-quantification of organ motion and set-up errors in external beam radiation therapy. Computer Aided Surg 5: 289-295

Lattanzi J, McNeeley S, Pinover W, Horwitz E, Das I, Schultheiss TE, Hanks GE (1999) A comparison of daily CT localization to a daily ultrasoundbased system in prostate cancer (see comment). Int J Radiat Oncol Biol Phys 43: $719-725$

Lee N, Xia P, Quivey JM, Sultanem K, Poon I, Akazawa C, Akazawa P, Weinberg V, Fu KK (2002) Intensity-modulated radiotherapy in the treatment of nasopharyngeal carcinoma: an update of the UCSF experience (see comment). Int J Radiat Oncol Biol Phys 53: 12-22

Levendag P, Braaksma M, Coche E, van Der Est H, Hamoir M, Muller K, Noever I, Nowak P, van Sorensen De Koste J, Gregoire V (2004) Rotterdam and Brussels CT-based neck nodal delineation compared with the surgical levels as defined by the American Academy of Otolaryngology-Head and Neck Surgery (see comment). Int J Radiat Oncol Biol Phys 58: $113-123$

Ling CC, Burman C, Chui CS, Kutcher GJ, Leibel SA, LoSasso T, Mohan R, Bortfeld T, Reinstein L, Spirou S, Wang XH, Wu Q, Zelefsky M, Fuks Z (1996) Conformal radiation treatment of prostate cancer using inverselyplanned intensity-modulated photon beams produced with dynamic multileaf collimation (see comment). Int J Radiat Oncol Biol Phys 35: $721-730$

Mackie TR, Balog J, Ruchala K, Shepard D, Aldridge S, Fitchard E, Reckwerdt P, Olivera G, McNutt T, Mehta M (1999) Tomotherapy. Semin Radiat Oncol 9: 108-117

Mackie TR, Kapatoes J, Ruchala K, Lu W, Wu C, Olivera G, Forrest L, Tome W, Welsh J, Jeraj R, Harari P, Reckwerdt P, Paliwal B, Ritter M, Keller H, Fowler J, Mehta M (2003) Image guidance for precise conformal radiotherapy. Int J Radiat Oncol Biol Phys 56: 89-105

Mell LK, Roeske JC, Mundt AJ (2003) A survey of intensity-modulated radiation therapy use in the United States. Cancer 98: 204-211

Michalski JM, Purdy JA, Winter K, Roach III M, Vijayakumar S, Sandler HM, Markoe AM, Ritter MA, Russell KJ, Sailer S, Harms WB, Perez CA, Wilder RB, Hanks GE, Cox JD (2000) Preliminary report of toxicity following 3D radiation therapy for prostate cancer on 3DOG/RTOG 9406. Int J Radiat Oncol Biol Phys 46: 391-402

Nederveen AJ, Dehnad H, van der Heide UA, van Moorselaar RJ, Hofman P Lagendijk JJ (2003) Comparison of megavoltage position verification for prostate irradiation based on bony anatomy and implanted fiducials. Radiother Oncol 68: $81-88$

Nguyen LN, Pollack A, Zagars GK (1998) Late effects after radiotherapy for prostate cancer in a randomized dose-response study: results of a selfassessment questionnaire. Urology 51: $991-997$

Orton NP, Tome WA (2004) The impact of daily shifts on prostate IMRT dose distributions. Med Phys 31: 2845-2848

Parliament MB, Scrimger RA, Anderson SG, Kurien EC, Thompson HK, Field GC, Hanson J (2004) Preservation of oral health-related quality of life and salivary flow rates after inverse-planned intensity- modulated radiotherapy (IMRT) for head-and-neck cancer. Int J Radiat Oncol Biol Phys 58: 663-673

Patel RR, Orton N, Tome WA, Chappell R, Ritter MA (2003) Rectal dose sparing with a balloon catheter and ultrasound localization in conformal radiation therapy for prostate cancer. Radiother Oncol 67: 285-294

Pollack A, Hanlon AL, Horwitz EM, Feigenberg SJ, Uzzo RG, Hanks GE (2004) Prostate cancer radiotherapy dose response: an update of the fox chase experience. J Urol 171: 1132-1136

Pollack A, Zagars GK, Starkschall G, Antolak JA, Lee JJ, Huang E, von Eschenbach AC, Kuban DA, Rosen I (2002) Prostate cancer radiation dose response: results of the M. D. Anderson phase III randomized trial (see comment). Int J Radiat Oncol Biol Phys 53: 1097-1105

Reddy SP, Leman CR, Marks JE, Emami B (2001) Parotid-sparing irradiation for cancer of the oral cavity: maintenance of oral nutrition and body weight by preserving parotid function. Am J Clin Oncol 24: $341-346$

Richardson SL, Tome WA, Orton NP, McNutt TR, Paliwal BR (2003) IMRT delivery verification using a spiral phantom. Med Phys 30: 2553-2558

Tucker SL, Cheung R, Dong L, Liu HH, Thames HD, Huang EH, Kuban D, Mohan R (2004) Dose-volume response analyses of late rectal bleeding after radiotherapy for prostate cancer. Int J Radiat Oncol Biol Phys 59: $353-365$

Wachter S, Gerstner N, Dorner D, Goldner G, Colotto A, Wambersie A, Potter R (2002) The influence of a rectal balloon tube as internal immobilization device on variations of volumes and dose-volume histograms during treatment course of conformal radiotherapy for prostate cancer. Int J Radiat Oncol Biol Phys 52: $91-100$

Zelefsky MJ, Fuks Z, Hunt M, Yamada Y, Marion C, Ling CC, Amols H, Venkatraman ES, Leibel SA (2002) High-dose intensity modulated radiation therapy for prostate cancer: early toxicity and biochemical outcome in 772 patients. Int J Radiat Oncol Biol Phys 53: 1111-1116

Zelefsky MJ, Leibel SA, Gaudin PB, Kutcher GJ, Fleshner NE, Venkatramen ES, Reuter VE, Fair WR, Ling CC, Fuks Z (1998a) Dose escalation with three-dimensional conformal radiation therapy affects the outcome in prostate cancer (see comment). Int J Radiat Oncol Biol Phys 41: 491-500

Zelefsky MJ, Leibel SA, Kutcher GJ, Fuks Z (1998b) Three-dimensional conformal radiotherapy and dose escalation: where do we stand? Semin Radiat Oncol 8: 107-114 